Original Article

Volume: 6 Issue: 1 pp:42-52 2019
Journal of Athletic Performance and Nutrition

https://doi.org/10.31131/japn-2019-0001/4

\title{
The Relationship Between Body Image, Eating Behavior and Nutritional Status for Female Athletes
}

\author{
${ }^{1}$ Selen MÜFTÜOĞLU, ${ }^{1}$ Dilara İÇBUDAK
}

\begin{abstract}
Received Date: 19.02.2019
Accepted Date: 17.05.2019
\end{abstract}

\begin{abstract}
Objectives: The present study was conducted by using the cross-sectional study design and to determine the relationship between body image, eating behavior and nutritional status in female athletes. Methods: This study was conducted by using the cross-sectional study design and the sample was comprised of 80 female athletes who volunteered to participate in the study between January and March of 2018. Findings: This study demonstrated that $70.0 \%$ of the female athletes had skipped a meal. Also, female athletes had a normal BMI but $65.0 \%$ of them indicated that want to be thinner. On the other hand, we analyzed that their daily nutrients intake, so we observed that $43.4 \%$ of the energy was from the fatty acids, especially saturated fatty acids, and they had lower fiber, calcium and iron intake. Also, we found that BMI, waist circumference, waist to hip ratio were negatively correlated with Multidimensional Body-Self Relations Questionnaire and The Dutch Eating Behavior Questionnaire score and they were lower in who had meal skipped or not received diet therapy. Conclusion: The findings of this study indicate that nutrition education is frequently neglected in sports programs. There is a paucity of nutrition education interventions among different sports.
\end{abstract}

Key words: Female Athletes, Body Image, Eating Behavior, Eating Disorders, Nutritional Status

${ }^{1}$ Department of Nutrition and Dietetics, Faculty of Health Sciences, Baskent University, Ankara, Turkey.

\section{Introduction}

Body image is a broad and dynamic concept that extends across perceptual and attitudinal modalities (Varnes et al., 2013; Pepe, Özdemir \& Mustafa, 2015). The term body image is an extensive term encompassing many constructs. These include, but are not limited to: weight (dis)satisfaction, body (dis)satisfaction, body shame, appearance (dis)satisfaction, appearance evaluation, body esteem, body appreciation, body dysmorphia and body schema (Tylka \& Wood-Barcalow, 2015; Moradi \& Varnes, 2017;). Especially among female athletes, 
body image is associated with several heath issues such as disordered eating, mood disorders, decreased self-esteem or nutrient deficency (Piacentino et al., 2017; Nikiforos et al., 2017; Robbeson, Kruger \& Wright, 2015).

Actually, it is expected higher body image perception in the athletes. However, since the turn of the 21 st Century, the sexual objectification of especially female athletes in the media has increased and the definition of ideal female beauty now includes appearing athletic, in addition to being thin (Kantanista et al., 2018; Kim, Sagas \& Walker, 2011; Daniels, 2009; Kafkas et al., 2014). So these changes are caused a great under pressure in the female athletes on body image perception (de Oliveira et al., 2017). On the other hand, some studies have suggested a higher frequency of eating problems in female athletes, particularly in athletes competing in sports that emphasize leanness or a low body weight (Fatima, Noor, Khan, Bashir \& Fatima, 2018; Plateau, Arcelus, Leung \& Meyer, 2017). Meyers (2015), et al found that $50.7 \%$ athletes were at risk of eating disorders. In another study showed that mostly college athletes had low EAT- 26 score which leads to dieting, fasting and disordered eating behaviors (Kalista et. al, 2014). Another study with 224 elite Australian athletes of which 118 were females and 106 were males showed that, $46.4 \%$ of them were suffering from mental disorders including depression (27.2\%), eating disorder (22.8\%), general psychological anxiety, social illness (14.7\%), generalized anxiety disorder (7.1\%) and panic disorder (4.5\%) (Gulliver et al., 2015).

Generally, nutrition plays an important role in sports performance because it helps an athlete to maintain ideal body weight, body composition specific to sports and faster recovery (Beck, Thomson, Swift \& Von Hurst, 2015). However, calorie deficit and higher fat intake especially saturated fat and dietary cholesterol, was observed in female athletes such as soccer players, runners, rhythmic gymnasts, volleyball players and weightlifters compared to recommendations (Braun, von Andrian-Werburg, Schänzer \& Thevis, 2018; Naughton et al., 2016; Martin, Lambeth \& Scott, 2006).

These results suggest that athletes constitute a unique population, especially impact of factors such as training, eating pattern, extreme diets, restriction of food intake and psychopathological profile. Therefore, the present study was conducted to determine the relationship between body image, eating behavior and nutritional status in female athletes.

\section{Methods}

This study was conducted by using the cross-sectional study design and the sample was comprised of 80 female athletes who volunteered to participate in the study between January 
and March of 2018. Exclusion criteria included gender, pregnancy and lactation. Data were collected through self-administered questionnaires. Meanwhile for BMI, height and weight were taken to be classified based on WHO Global Database on Body Mass Index (WHO, 2008). Respondents who have a BMI lower than $18.50 \mathrm{~kg} / \mathrm{m}^{2}$ was classified under the category of underweight. The normal range that is considered as ideal BMI range is 18.50 to $24.99 \mathrm{~kg} / \mathrm{m}^{2}$. However, BMI that is within the range of 25.00 to $29.99 \mathrm{~kg} / \mathrm{m}^{2}$ and those who are over than $30.00 \mathrm{~kg} / \mathrm{m}^{2}$ was categorized under the overweight and obese category respectively. Additionally, waist and hip circumferences were taken to be classified based on Waist Circumference and Waist-Hip Ratio Report of a WHO Expert Consultation (WHO, 2011). The recommended sex-specific cut-off points for the waist circumferences of women are $80 \mathrm{~cm}$ for increased risk, $88 \mathrm{~cm}$ for substantially increased risk; waist-hip ratio of women are $\geq 0.85 \mathrm{~cm}$ for substantially increased risk.

Nutritional behavior of participants was determined by food consumption frequency. Nutrient Database (BeBiS, Ebispro for Windows, Germany; Turkish Version/BeBiS 7) was used to determine energy and nutrient intake; results were compared to Dietary Guidelines for Turkey (Dietary Guidelines for Turkey, 2006). Additionally, eating behaviors of participants was determined by The Dutch Eating Behavior Questionnaire (DEBQ). DEBQ is a 33-item self-report questionnaire to assess three distinct eating behaviors in adults: (1) emotional eating, (2) external eating, and (3) restrained eating (Bozan, Bas \& Asci, 2011). Items on the DEBQ range from 1 (never) to 5 (very often), with higher scores indicating greater endorsement of the eating behavior. Perceptions of body image were measured using Multidimensional Body-Self Relations Questionnaire (MBSRQ). The measurement is the composite of the 12 items and higher scores indicate greater behavioral and attitudinal investment in appearance (Dogan, 1992).

Data were analysed with SPSS version 17.0 (Inc.,Chicago, IL, USA). Comparisons groups were made using the Mann-Whitney U test. Both the Pearson and Spearman Rank Order coefficient were used to test for possible correlations among the different variables tested, depending on whether the data were normally distributed or not. $p<0.05$ was set as statistically significant.

\section{Results}

This study has successfully interviewed 80 female athletes in Ankara, Turkey. As shown in Table 1, the mean ages of athletes were $22.5 \pm 6.78$ years and $92.5 \%$ of them were the college graduate. For the "classification of the sport" majorly 35.0\% of them were basketball players 
and $28.8 \%$ of them were volleyball players. Athletes have been training 3.94 \pm 1.85 days a week and $2.16 \pm 0.96$ hours a day. Based on the mean BMI of the athletes was $22.7 \pm 3.14 \mathrm{~kg} / \mathrm{m}^{2}$ and the mean waist circimference was $76.0 \pm 9.12 \mathrm{~cm}$.

\section{Table 1. Characteristics data of athletes}

\begin{tabular}{|c|c|c|}
\hline Characteristics & n (80) & $\%$ \\
\hline \multicolumn{3}{|l|}{ Classification } \\
\hline Basketball & 28 & 35.0 \\
\hline Volleyball & 23 & 28.8 \\
\hline Flag football & 15 & 18.8 \\
\hline Indoor soccer & 8 & 10.0 \\
\hline Ice hokey & 6 & 7.4 \\
\hline \multicolumn{3}{|l|}{ Education level } \\
\hline High school graduate & 1 & 1.2 \\
\hline College graduate & 74 & 92.5 \\
\hline Master / PhD graduate & 5 & 6.3 \\
\hline Age, mean $( \pm S D)$ & \multicolumn{2}{|c|}{$22.5 \pm 6.78$} \\
\hline Training (day/week) & \multicolumn{2}{|c|}{$3.94 \pm 1.85$} \\
\hline Training (hours/day) & \multicolumn{2}{|c|}{$2.16 \pm 0.96$} \\
\hline$B M I,\left(k g / m^{2}\right)$ & \multicolumn{2}{|c|}{$22.7 \pm 3.14$} \\
\hline Waist curcimference, (cm) & \multicolumn{2}{|c|}{$76.0 \pm 9.12$} \\
\hline Wasit to hip ratio, $(\mathrm{cm})$ & \multicolumn{2}{|c|}{$0.73 \pm 0.70$} \\
\hline
\end{tabular}

Overall, we found that $70.0 \%$ of the athletes had skipped a meal and most skipped meal was breakfast $(53.3 \%)$. In this study, the mean of the number of main meals was $2.45 \pm 0.63$ and snacks was $1.97 \pm 1.07$. The mean DEBQ score for athletes was $91.3 \pm 24.49 .65 .0 \%$ of athletes said that want to be thinner and $68.7 \%$ of them had a diet therapy before.

Daily mean energy $(1984.3 \pm 816.42 \mathrm{kcal})$ and nutrient intake were assessed and we observed that $43.4 \%$ of the energy was from the fatty acids, especially saturated fatty acids (49.1 \pm 10.32$)$.

Additionally, lower nutrient intake level was assessed and we found that daily fiber intake was $19.6 \pm 10.86 \mathrm{gr}$, calcium intake was $277.0 \pm 123.79 \mathrm{mg}$ and iron intake was $12.5 \pm 4.99$ mg (Table 2). 
Table 2. Eating behaviors and nutritional status of athletes

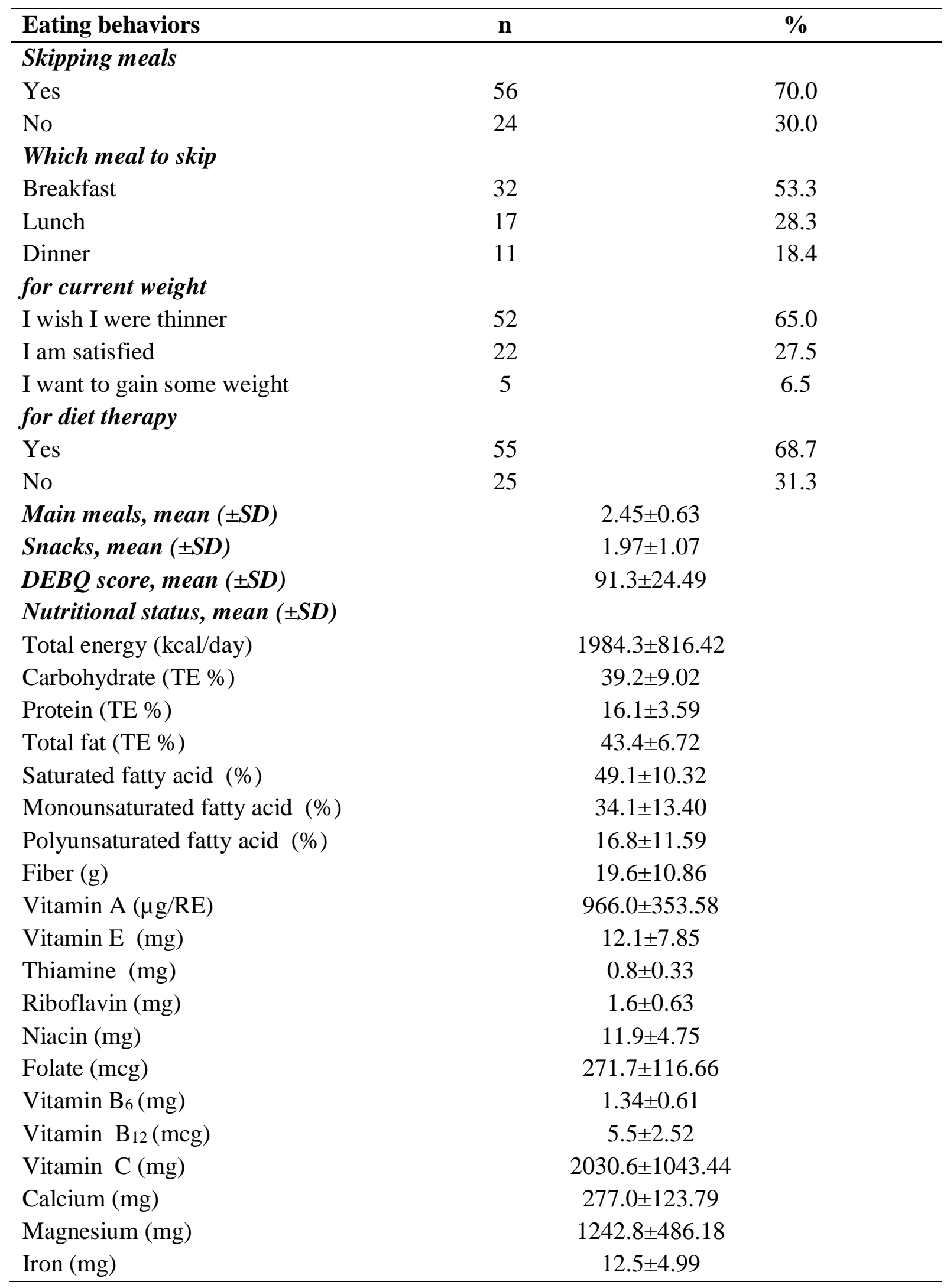


In this study, we assessed body image perception among athletes and we found that the mean MBSRQ score was 198.0 \pm 30.90 . Table 3 shows that the correlation between body image perception, eating behaviors, nutritional status and some characteristics. Accordingly, age was negatively correlated with MBSRQ score $(r=0.279, p=0.01)$. BMI, waist circumference, waist to hip ratio were negatively correlated with MBSRQ and DEBQ score but these differences were not statistically significant. Additionally, the main meals number were negatively correlated with DEBQ score $(r=-0.361, p=0.00)$. MBSRQ and DEBQ score was lower in who had meal skipped or not received diet trehapy but the differences were not statistically significant (Table 3).

Table 3. Correlation between body image perception, eating behaviors, nutritional status and some characteristics

\begin{tabular}{|c|c|c|c|c|}
\hline & \multicolumn{2}{|c|}{ MBSRQ score } & \multicolumn{2}{|c|}{ DEBQ score } \\
\hline & $\mathbf{r}$ & $\mathbf{p}$ & $\mathbf{r}$ & $\mathbf{p}$ \\
\hline \multicolumn{5}{|l|}{ Characteristics } \\
\hline Age & -0.279 & $0.01^{*}$ & -0.125 & 0.26 \\
\hline Training (day/week) & 0.059 & 0.60 & 0.108 & 0.34 \\
\hline Training (hours/day) & 0.066 & 0.56 & 0.052 & 0.64 \\
\hline$B M I,\left(\mathrm{~kg} / \mathrm{m}^{2}\right)$ & -0.016 & 0.14 & -0.008 & 0.94 \\
\hline Waist curcimference, $(\mathrm{cm})$ & -0.010 & 0.35 & -0.020 & 0.98 \\
\hline Wasit to hip ratio, $(\mathrm{cm})$ & -0.006 & 0.95 & -0.103 & 0.36 \\
\hline Classification of sports & 0.098 & 0.38 & 0.017 & 0.88 \\
\hline \multicolumn{5}{|l|}{ Eating habits } \\
\hline Number of main meals & -0.019 & 0.86 & $-0.361^{*}$ & 0.00 \\
\hline Number of snacks & 0.129 & 0.25 & 0.093 & 0.41 \\
\hline Skipping meals & -0.009 & 0.93 & -0.062 & 0.58 \\
\hline Diet treatment & 0.009 & 0.93 & 0.088 & 0.43 \\
\hline \multicolumn{5}{|l|}{ Nutritional status } \\
\hline Total energy (kcal/day) & -0.129 & 0.25 & -0.235 & $0.04^{*}$ \\
\hline Carbohydrate (TE \%) & -0.211 & 0.06 & 0.087 & 0.44 \\
\hline Protein (TE \%) & 0.282 & $0.01^{*}$ & 0.049 & 0.66 \\
\hline Total fat (TE \%) & 0.135 & 0.23 & 0.052 & 0.64 \\
\hline Saturated fatty acid (\%) & 0.023 & 0.75 & 0.075 & 0.29 \\
\hline Monounsaturated fatty acid (\%) & 0.030 & 0.68 & 0.078 & 0.27 \\
\hline Polyunsaturated fatty acid (\%) & 0.014 & 0.85 & 0.065 & 0.36 \\
\hline Fiber $(g)$ & 0.024 & 0.83 & 0.053 & 0.45 \\
\hline Vitamin $A(\mu g / R E)$ & 0.118 & 0.09 & 0.005 & 0.94 \\
\hline Vitamin E (mg) & 0.017 & 0.81 & 0.058 & 0.41 \\
\hline Thiamine (mg) & 0.005 & 0.94 & 0.096 & 0.18 \\
\hline Riboflavin (mg) & 0.044 & 0.54 & 0.015 & 0.83 \\
\hline $\operatorname{Niacin}(m g)$ & 0.027 & 0.71 & 0.065 & 0.36 \\
\hline Folate (mcg) & 0.062 & 0.39 & 0.105 & 0.14 \\
\hline Vitamin $B_{6}(m g)$ & 0.184 & $0.01 *$ & 0.130 & 0.07 \\
\hline Vitamin $B_{12}(m c g)$ & 0.173 & $0.01 *$ & 0.044 & 0.54 \\
\hline Vitamin $C(m g)$ & 0.032 & 0.65 & 0.078 & 0.27 \\
\hline Calcium (mg) & 0.189 & $0.01 *$ & 0.036 & 0.61 \\
\hline Magnesium (mg) & 0.078 & 0.27 & 0.045 & 0.52 \\
\hline Iron (mg) & 0.210 & $0.01 *$ & 0.055 & 0.44 \\
\hline
\end{tabular}


We analyzed the nutritional status of the athletes and MBSRQ score was negatively correlated with energy and carbohydrate (TE\%), but only MBSRQ score was positively correlated with protein intake $(\mathrm{TE} \%)(\mathrm{r}=0.282, \mathrm{p}=0.01)$. Only, MBSRQ score was positively correlated with vitamin $\mathrm{B}_{6}(\mathrm{r}=184, \mathrm{p}=0.01)$, vitamin $\mathrm{B}_{12}(\mathrm{r}=0.173, \mathrm{p}=0.01)$, calcium $(\mathrm{r}=0.189$, $\mathrm{p}=0.01)$ and iron $(\mathrm{r}=0.210, \mathrm{p}=0.01)$ intake. Similarly, a positive correlation was found between DEBQ score and all macro-micro nutrient but these correlations were not statistically significant. Only, DEBQ score was negatively correlated with total energy intake $(r=-0.235$, $\mathrm{p}=0.04)($ Table 3).

\section{Discussion}

This study demonstrated that $70.0 \%$ of the female athletes had skipped meal. Also, female athletes had a normal BMI but $65.0 \%$ of them indicated that want to be thinner. On the other hand, we analyzed that their daily nutrients intake, so we observed that $43.4 \%$ of the energy was from the fatty acids, especially saturated fatty acids, and they had lower fiber, calcium and iron intake. The studies about nutrition status among athletes show that daily low energy intake, a combination of percentage calories from carbohydrate less than $50 \%$, protein greater than $20 \%$ and fat greater than $30 \%$ of total energy. For example, Zapolska et al. found that the percentage of daily calories intake was $45.9 \%$ from carbohydrate, $21.3 \%$ from protein and $32.8 \%$ from fat among female professional volleyball players in Poland (Zapolska, Witczak, Manczuk \&Ostrowska, 2014).

Similirlay, Chung, Siu \& Chan (2012) indicated that that the percentage of daily calories intake was $51.0 \%$ from carbohydrate, $16.0 \%$ from protein and $32.0 \%$ from fat in both gender among elite athletes in Hong Kong. Some studies have shown that micronutrient intake was below the recommendations in athletes. For example lower calcium, folate, zinc, iron, vitamin $\mathrm{A}$, vitamin $\mathrm{C}$ intake was observed in female athletes such as female volley ball players, national female soccer players, female elite aquatic athlete, female national level rhythmic gymnasts, professional weightlifters exc (Hima Bindu Malla, Dhingra \& Lal, 2017).

Eating behavior of athletes is affected by various stimuli present in their environment. Attitudes play an important role in the adoption and maintenance of a variety of health and nutritional habits. Especially studies have shown that athletes are more prone to developing eating disorders (Kong \& Harris, 2015; Churchill, 2014). Among athletes, the prevalence of eating disorders was 23-25\% and disordered eating was 15-62\% (Joy, Kussman \& Nattiv, 2016). There is strong and consistent evidence that eating disorders are prevalent in weight sensitive sports and higher in females than in males (Currie, 2010). In this study we found that 
the atheletes had a normal BMI but $65.0 \%$ of them indicated that want to be thinner. Additionaly, the mean DEBQ score for athletes was 91.3 \pm 24.49 . The minimum and maximum scores obtained from the DEBQ was 33,165, respectively and higher scores indicating greater endorsement of the eating behavior. So, firstly we found that BMI, waist circumference, waist to hip ratio were negatively correlated with DEBQ score and it was lower in who had meal skipped or not received diet trehapy. In addition total energy intake and the main meals number were negatively correlated with DEBQ score.

Additionally, body image perception, negative perfectionism and social physique anxiety influence disordered eating and eating disorders in elite athletes (Kong \& Harris, 2015). Body image dissatisfaction trigger factors associated with the onset of were prolonged periods of dieting, frequent weight fluctuations, the sudden increase in training volume and traumatic events such as injury (Kosteli, Van Raalte, Brewer \& Cornelius, 2014). Accordingly, we assessed body image perception among athletes and we used to MBSRQ. So, in this study, we found that BMI, waist circumference, waist to hip ratio were negatively correlated with MBSRQ score and it was lower in who had meal skipped or not received diet therapy. Also we found that MBSRQ score was positively relationship with many micro nutrient intake especially vitamin $\mathrm{B}_{6}$, vitamin $\mathrm{B}_{12}$, calcium and iron $(\mathrm{p}<0.05)$.

\section{Conclusions}

As a conclusion, the results of the current study may help to determine the knowledge about the body image perceptions and eating behavior among female athletes in Ankara, Turkey. Firstly, coaches, parents or others should focus on highlighting the importance of healthy body image to prevent the sprouting of the seed of doubt regarding their body. Secondly, nutrition education is needed to improve nutrition knowledge and bring changes in dietary practices. Nutrition-education programs are often based on the premise that superior nutrition knowledge may translate into the better dietary intake. Nutrition education is frequently neglected in sports programs. There is a paucity of nutrition education interventions among different sports. More studies are needed to be done in this area \& provide right information \& encourage athletes to bring healthy changes in their diet.

\section{Disclosure statement}

No potential conflict of interest was reported by the authors. 


\section{References}

Beck, K. L., Thomson, J. S., Swift, R. J., \& Von Hurst, P. R. (2015). Role of nutrition in performance enhancement and postexercise recovery. Open access journal of sports medicine, 6, 259.

Braun, H., von Andrian-Werburg, J., Schänzer, W., \& Thevis, M. (2018). Nutrition Status of Young elite female German football players. Pediatric exercise science, 30(1), 157-167.

Bozan, N., Bas, M., \& Asci, F. H. (2011). Psychometric properties of Turkish version of Dutch Eating Behavior Questionnaire (DEBQ). A preliminary result. Appetite, 56(3), 564-566.

Chung, S., Siu, P. L. F., \& Chan, C. Y. C. (2012). Nutrition, Physical activity and Bone Mineral Density of hong Kong elite athletes. Nutrition, 1-2.

Churchill, W. (2014). Future Directions with Treatment, Training, and Research. Changing Self-Destructive Habits: Pathways to Solutions with Couples and Families, 309.

Currie, A. (2010). Sport and eating disorders-understanding and managing the risks. Asian journal of sports medicine, 1(2), 63.

Daniels, E. A. (2009). Sex objects, athletes, and sexy athletes: How media representations of women athletes can impact adolescent girls and college women. Journal of Adolescent Research, 24(4), 399-422.

de Oliveira, G. L., de Oliveira, T. A. P., de Pinho Gonçalves, P. S., Valentim Silva, J. R., Roquetti Fernandes, P., \& Fernandes Filho, J. (2017). Body Image and Eating Disorders in Female Athletes of Different Sports. Journal of Exercise Physiology Online, 20(2).

Dietary Guidelines for Turkey (2006) Recommended Safe Level of Intake of Energy and Nutrients for Turkey, The Ministry of Health of Turkey, The General Directorate of Primary Health Care, Ankara, Turkey.

Dogan, O., \& Dogan, S. (1992). Handbook of the Multidimensional Body-Self Relations Questionnaire.

Fatima, S., Noor, R., Khan, I., Bashir, M. S., \& Fatima, M. (2018). Level of anxiety and disordered eating behavior among young female athletes. Rawal Medical Journal, 43(1), 45-47.

Gulliver, A., Griffiths, K. M., Mackinnon, A., Batterham, P. J., \& Stanimirovic, R. (2015). The mental health of Australian elite athletes. Journal of science and medicine in sport, 18(3), 255-261.

Hima Bindu Malla, D., Dhingra, M., \& Lal, P. R. (2017). Nutritional status of athletes: A review. International Journal of Physiology, Nutrition and Physical Education 2017; 2(2): $895-904$ 
Joy, E., Kussman, A., \& Nattiv, A. (2016). 2016 update on eating disorders in athletes: A comprehensive narrative review with a focus on clinical assessment and management. Br J Sports Med, 50(3), 154-162.

Kafkas, M. E., Durmuş, B., Kafkas, A., Açak. M. \& Aydın, A. (2014). The effects of different exercise programs on knee muscle strength and $\mathrm{H}: \mathrm{Q}$ ratios of sedentary males and females. Journal of Athletic Performance and Nutrition, 1(2).

Kalista, M., Phillips, S., Clarke, T., Silbernagel, S., Martin, N., \& Papadopoulos, C. (2014). Nutritıonal Intake, Eatıng Attıtude, And Anxıety Among Collegiate Softball Players: A Descriptive Study. In International Journal of Exercise Science: Conference Proceedings, 8:2-43.

Kantanista, A., Glapa, A., Banio, A., Firek, W., Ingarden, A., Malchrowicz-Mośko, E., ... \& Maćkowiak, Z. (2018). Body image of highly trained female athletes engaged in different types of sport. BioMed research international, 2018.

Kim, K., Sagas, M., \& Walker, N. A. (2011). Replacing athleticism with sexuality: Athlete models in Sports Illustrated swimsuit issues. International Journal of Sport Communication, 4(2), 148-162.

Kong, P., \& Harris, L. M. (2015). The sporting body: body image and eating disorder symptomatology among female athletes from leanness focused and nonleanness focused sports. The Journal of psychology, 149(2), 141-160.

Kosteli, M. C., Van Raalte, J. L., Brewer, B. W., \& Cornelius, A. E. (2014). Relationship between sport type and body image of female athletes. TRENDS in Sport Sciences, 21(2), 65-72.

Martin, L., Lambeth, A., \& Scott, D. (2006). Nutritional practices of national female soccer players: Analysis and recommendations. Journal of sports science \& medicine, 5(1), 130.

Meyers, J. T. (2015). Prevalence of eating disorders and disordered eating among female collegiate varsity and club sport athletes: A systematic review (Doctoral dissertation, Purdue University).

Moradi, B., \& Varnes, J. R. (2017). Structure of the Objectified Body Consciousness Scale: Reevaluated 20 Years later. Sex Roles, 77(5-6), 325-337.

Naughton, R. J., Drust, B., O’Boyle, A., Morgans, R., Abayomi, J., Davies, I. G., ... \& Mahon, E. (2016). Daily distribution of carbohydrate, protein and fat intake in elite youth academy soccer players over a 7-day training period. International journal of sport nutrition and exercise metabolism, 26(5), 473-480. 
Nikiforos, G., George, K., Ilias, A., Onur, O., Eleftherios, T., Fares, S., \& John, K. (2017). Dietary Intakes and Nutritional Status of a Greek Team of Female Volleyball Players. Arab Journal of Nutrition and Exercise (AJNE), 1(1), 1-14.

Pepe, O., Atar, Ö., \& Koç, M. (2015). Health Promoting Behaviours of Sub-Elite Athletes. Journal of Athletic Performance and Nutrition, 2(1).

Plateau, C. R., Arcelus, J., Leung, N., \& Meyer, C. (2017). Female athlete experiences of seeking and receiving treatment for an eating disorder. Eating disorders, 25(3), 273277.

Piacentino, D., Kotzalidis, G. D., Longo, L., Pavan, A., Stivali, L., Stivali, G., ... \& Girardi, P. (2017). Body image and eating disorders are common among professional and amateur athletes using performance and image enhancing drugs: a cross-sectional study. Journal of psychoactive drugs, 49(5), 373-384.

Robbeson, J. G., Kruger, H. S., \& Wright, H. H. (2015). Disordered eating behavior, body image, and energy status of female student dancers. International journal of sport nutrition and exercise metabolism, 25(4), 344-352.

Tylka, T. L., \& Wood-Barcalow, N. L. (2015). The Body Appreciation Scale-2: item refinement and psychometric evaluation. Body image, 12, 53-67.

Varnes, J. R., Stellefson, M. L., Janelle, C. M., Dorman, S. M., Dodd, V., \& Miller, M. D. (2013). A systematic review of studies comparing body image concerns among female college athletes and non-athletes, 1997-2012. Body image, 10(4), 421-432.

Zapolska, J., Witczak, K., Manczuk, A., \& Ostrowska, L. (2014). Assessment of nutrition, supplementation and body composition parameters on the example of professional volleyball players. Roczniki Państwowego Zakładu Higieny, 65(3).

WHO. (2008). Global database on body mass index.

World Health Organization. (2011). Waist circumference and waist-hip ratio: report of a WHO expert consultation, Geneva, 8-11 December 2008. 